\title{
"PEPRADASE" \\ PELATIHAN PRAKTIKUM BIOLOGI DENGAN ALAT DAN BAHAN SEDERHANA
}

\author{
Fitri Agustina Lubis ${ }^{1)}$; Jalilah Azizah Lubis ${ }^{2)}$; Mutiara Lubis ${ }^{3)}$ \\ ${ }^{1,2,3)}$ Pendidikan Biologi, FKIP Universitas Muhammadiyah Tapanuli Selatan \\ jalilah_azizah@ymail.com
}

\begin{abstract}
Objectives of the Activity This training is expected to be more creative in teaching practicum and teaching planning by applying the right strategy to develop teachers' creativity in using simple tools and materials when practicum and student interest to learn more in improving scholarship in biology learning. This devotion is done in SMA Negeri 5 Kota Padangsidimpuan, the time of implementation is adjusted to the MGMP Teacher - High School Biology subject. This dedication is executed for two months from January - February 2017 where the activities are done for four days in thedifferentperiod.The result of this teaching materials development workshop is that the teachers of Biology at SMA Kota Padangsidimpuan have gained much motivation, related information / knowledge in developing lesson plan and making of practicum with simple materials also predicted in the future the teachers of Biology especially in SMA are able develop simple practice materials on their own.
\end{abstract}

Keywords: Training, Development of RPP, Simple Practicum.

\begin{abstract}
Abstrak
Tujuan Kegiatan Pelatihan ini diharapkan guru Biologi SMA lebih kreatif dalam melaksanakan praktikum dan perencanaan pengajarannya dengan menggunakan strategi yang tepat diharapkan mampu menumbuhkan kreativitas guru dalam menggunakan alat dan bahan yang sederhana pada saat praktikum dan minat siswa untuk lebih giat belajar lebih meningkatkan keilmiahan dalam belajar biologi. Pengabdian ini dilaksanakan di SMA Negeri 5 Kota Padangsidimpuan, waktu pelaksanaan disesuaikan dengan pertemuan MGMP GuruGuru SMA mata pelajaran Biologi. Pengabdian ini dilaksanakan selama 2 bulan dari bulan Januari-Februari 2017 dimana kegiatannya dikerjakan selama 4 hari dalam jangka waktu yang berbeda. Hasil workshop pengembangan bahan ajar ini yaitu bahwa guru-guru Biologi di SMA Se-Kota Padangsidimpuan sudah banyak memperoleh motivasi, informasi/pengetahuan terkait dalam pengembangan rencana pembelajaran dan pembuatan praktikum dengan bahan sederhana juga diperkirakan kedepannya para guru-guru Biologi khususnya di SMA sudah mampu mengembangkan bahan praktikum dengan sederhana sendiri.
\end{abstract}

Kata Kunci : Pelatihan, Pengembangan RPP, Praktikum Sederhana. 


\section{PENDAHULUAN}

Pembelajaran Biologi memiliki karakteristik yang berbeda dengan ilmu pengetahuan lain. Di mana karakteristik Biologi harus mampu berinteraksi langsung dengan mahluk hidup dan tidak dapat dipisahkan dengan laboratorium untuk melaksanakan praktikum. Selama ini kita merancang dan melaksanakan pembelajaran Biologi sesuai dengan apa yang kita pahami, didukung dengan pengalaman dan pengembangan di sekolah tentunya, persoalannya apakah yang kita rancang sudah sesuai dengan hakikat pembelajaran Biologi.

Pengamatan di sekolah dan hasil sharing dengan mahasiswa calon guru yang telah melaksanakan praktik di sekolah menunjukkan kecenderungan terdapatnya guru-guru yang membelajarkan siswanya dengan strategi/ metode yang kurang representative dan mendukung pemenuhan kebutuhan keilmuan Biologi. Dan masih jarang didukung dengan praktikum biologi, sedangkan praktikum adalah salah satu cara untuk meningkatkan hasil dan pengalaman langsung oleh para siswa. Ada empat alasan mengenai pentingnya praktikum Biologi, pertama praktikum membangkitkan motivasi belajar sains. Melalui kegiatan laboratorium, siswa diberi kesempatan untuk memenuhi dorongan rasa ingin tahu dan ingin bisa. Prinsip ini akan menunjang kegiatan praktikum dimana siswa menemukan pengetahuan melalui eksplorasinya terhadap alam. Kedua, Praktikum mengembangkan keterampilan dasar melakukan eksperimen (Anwar, 2014). Dengan kegiatan praktikum siswa dilatih untuk mengembangkan keterampilan dasar melakukan eksperimen dengan melatih kemampuan mereka dalam mengobservasi dengan cermat, mengukur secara akurat dengan alat ukur yang sederhana atau lebih canggih, menggunakan dan menangani alat secara aman, merancang, melakukan dan menginterprestasikan eksperimen. Ketiga, praktikum menjadi wahana belajar pendekatan ilmiah. Di dalam kegiatan praktikum, siswa dituntut untuk merumuskan masalah, merancang eksperimen, merakit alat, melakukan pengukuran secara cermat, menginterprestasi data perolehan, serta mengkomunikasikannya melalui laporan yang harus dibuatnya. Keempat, praktikum menunjang materi pelajaran.

Namun Kenyataannya, terkadang penyampaian informasi yang sarat dan dominan satu arah dari guru dengan ceramah, sedikitnya kesempatan dan ruang bagi siswa untuk berinteraksi dengan objek dan persoalan serta mengembangkan keterampilan berpikir tingkat tinggi, LKS yang tidak berfungsi optimal selain hanya untuk latihan soal-soal, adalah gambaran umum proses pembelajaran Biologi yang ada di sekolah. Belum lagi dengan tuntutan menuntaskan materi pelajaran, memaksa guru untuk semakin mengenyampingkan proses pembelajaran Biologi yang ideal. Pencapaian hasil belajar siswa pun menjadi terbatas pada aspek pengetahuan (kognitif) saja, tetapi belum banyak mengalami pengembangan aspek sensorimotorik, psikososial (afektif), dan nilainilai (values).

Dalam pelatihan guru biologi kami menjadikan pembelajaran biologi lebih mengarahkan praktikum memanfaatkan bahan sederhana yang mudah diperoleh. Hal ini nantinya dapat lebih menjadikan guru dalam memanfaatkan bahan sederhana yang digunakan sebagai bahan praktikum, memiliki kreativitas untuk 
Fitri Agustina Lubis, dkk. "PEPRADASE”Pelatihan Praktikum Biologi...

mengolah pembelajaran sehingga tidak membosankan melainkan sangat menyenangkan (Yuliati, 2008). Dampak positif yang diperoleh nantinya sangat banyak seperti (1) peningkatan pemahaman guru mengenai pengolahan pembelajaran, (2) mengetahui pengelolaan pembelajaran melalui praktikum sederhana, (3) guru nantinya tidak hanya dapat mengeluh dengan fasilitas yang kurang lengkap di sekolah, karena sudah terbiasa untuk memanfaatkan benda-benda sederhana di sekitarnya.

\section{METODE PELAKSANAAN}

Dalam pelaksanaan program pelatihan ini, tim IbM telah melakukan penyusunan rencana metode yang akan dilakukan selama proses awal sosialisasi dan rencana selama kegiatan berlangsung. Adapun dalam sosialisasi awal, tim IbM terlebih dahulu melakukan pertemuan dengan tim MGMP SMA Biologi Padangsidimpuan untuk mensosialisasikan kegiatan yang akan dilangsungkan.

Dalam sosialisasi awal, tim IbM memiliki tujuan agar terjadi komunikasi timbal balik tentang bagaimana cara yang efektif untuk mengajak guru-guru SMA mitra untuk ikut serta dalam kegiatan ini serta untuk mengetahui karakteristik para guru pada saat pelaksanaan praktikum tersebut.

Kegiatan pelatihan menggunakan Metode Training of Trainner (TOT) dengan cara pemberian materi melalui ceramah, kemudian dilanjutkan dengan praktik langsung oleh para guru. Cara ini dianggap efektif karena transfer pengetahuan yang diperoleh selama pelatihan akan lebih tersampaikan dengan baik jika peserta pelatihan itu sendiri yang menyampaikannya dan merasa bahwa kegiatan pelatihan tersebut bermanfaat bagi mereka.

\section{HASIL DAN PEMBAHASAN}

Kegiatan pada tahap pertama yaitu tim pengabdian masyarakat memotivasi para guru terkait betapa pentingnya mengembangkan bahan dan mempresentasikan ataupun membahas terkait proses pembuatan (RPP) K 13. Di mana RPP ini merupakan salah satu syarat dalam mengembangkan bahan ajar. Kegiatan ini dapat dikatakan terlaksana dengan baik hal ini didasari oleh antusias para peserta dalam mengikuti kegiatan. Ini dapat ditunjukkan berdasarkan banyaknya pertanyaan dari Para peserta. Selanjutnya adalah pelaksanaan praktek pelaksanaan (RPP) K 13 sesuai dengan penyusunannya. Guru-guru juga dikenalkan dengan pendekatan serta model-model pembelajaran K 13. Pendekatan disinkronkan dengan model pembelajaran di sana kami sebagai tim masih memiliki kendala karena masih banyak guru yang belum mampu betul untuk menyusun RPP dan langsung diaplikasikan ke dalam materi.

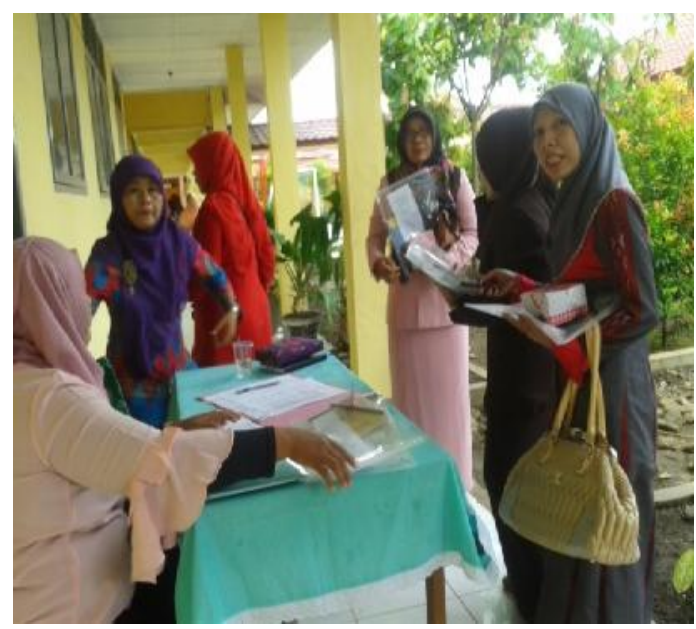

Gambar 1. Registrasi Peserta pada pelatihan PEPRADASE 


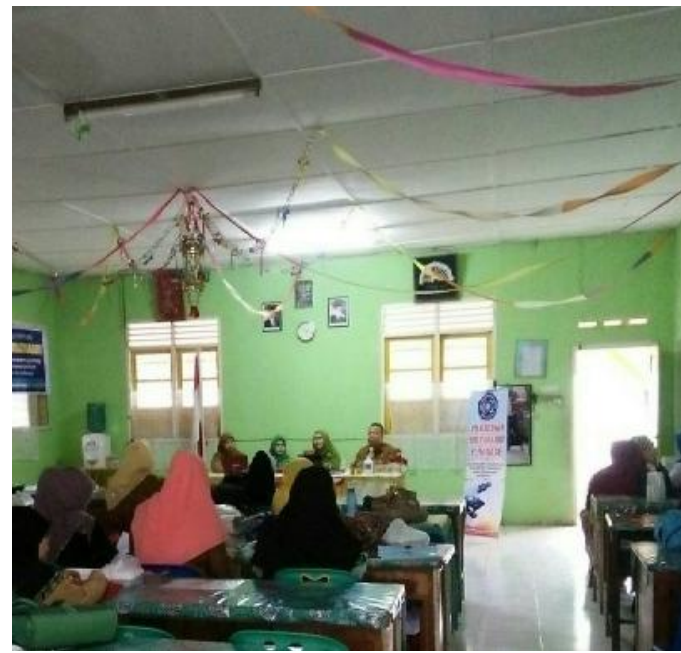

Gambar 2: Pembukaan Acara

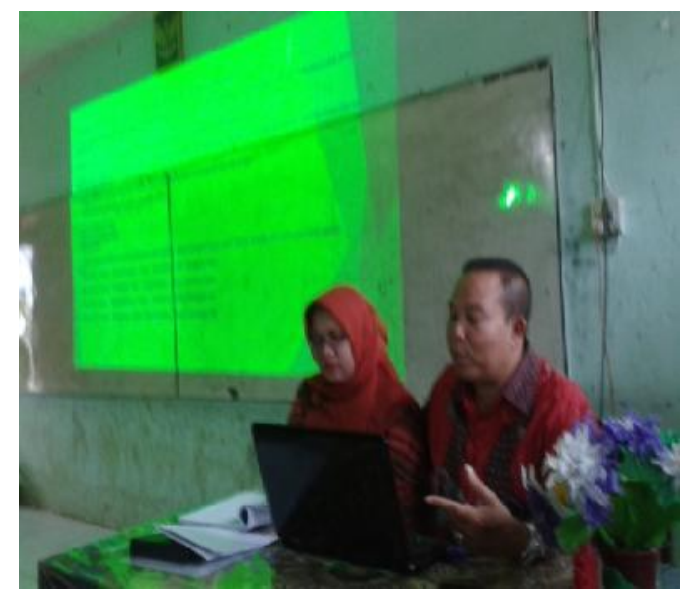

Gambar 3 : Presentasi Tugas kelompok

Pertanyaan yang diajukan oleh peserta kepada narasumber/pemateri:

(1) Bagaimana strategi pembelajaran yang tepat kita gunakan di kurikulum K13??

(2) Apa saja langkah pendekatan yan ada di dalam kurikulum K13?

(3) Bagaimana cara kita mengetahui Model pembelajaran yang tepat digunakan dalam proses pembelajaran?

(4) Dalam melaksanakan kegiatan proses pembelajaran kita harus memberikan nilai-nilai sikap kepada para siswa, bagaimana menilainya?
(5) Di dalam suatu kelas kemampuan siswa itu bervariasi ada yang pintar, sedang dan bodoh. Bagaimana cara mengetahuinya dengan cepat dan tepat?

(6) Dalam memilih strategi pembelajaran, kita harus mengetahui psikologi peserta didik. Jadi bagaimana kita bisa mengetahui psikologi peserta didik?

(7) Bagaimana strategi kita menghadapi orang tua dari peserta didik yang menyalahkan pendidik dalam mendidik anaknya disekolah? Padahal tugas mendidik anak adalah bukan di sekolah saja melainkan pengaruh yang paling besar ialah pendidikan keluarga.

(8) Strategi pembelajaran apa yang bisa kita terapkan ketika kita dihadapkan pada seluruh siswa dalam satu ruangan adalah siswa yang super aktif?

(9) Berdasarkan pertanyaan-pertanyaan yang diajukan para peserta workshop tersebut maka dapat dikatakan bahwa kegiatan berjalan dengan lancar sesuai yang diharapkan, menambah informasi dan pengetahuan bagi peserta ini didasari karena antusias peserta dalam mengikuti persentase dari awal sampai akhir kegiatan.

Kegiatan pada tahap kedua ini merupakan puncak dari kegiatan workshop karena pada hari ke dua pelaksanaan pengaplikasiaan RPP dengan praktikum. Pengembangan praktikum menggunakan alat dan bahan sederhana. Kegiatan ini juga didukung oleh LKS yang sudah disusun oleh seluruh peserta. Berdasarkan hasil pengamatan dan hasil pelaksanaan maka kegiatan workshop ini memberikan hal-hal yang baru bagi para peserta workshop dan sekaligus memberikan manfaat yang besar untuk perbaikan 
Fitri Agustina Lubis, dkk. "PEPRADASE”Pelatihan Praktikum Biologi...

pembelajaran kedepannya, diamana sebelumnya para guru belum pernah diberikan seminar/ workshop terkait penyusunan RPP sekaligus LKS dan praktikum.

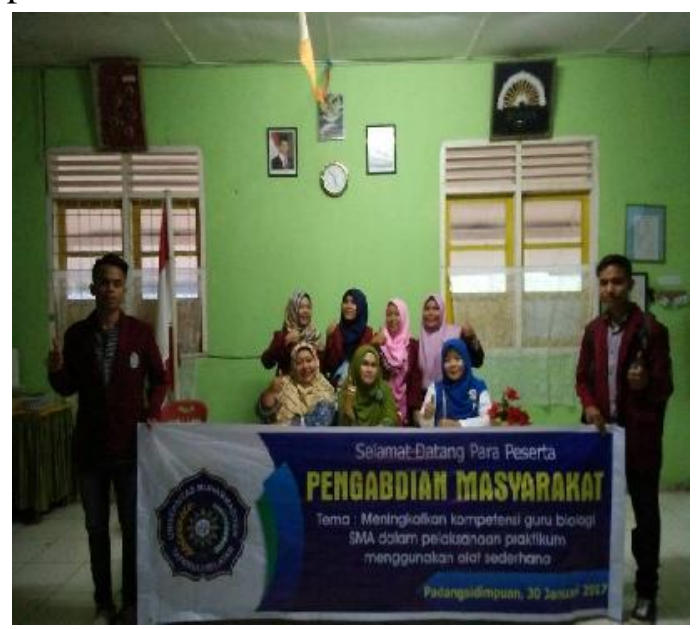

Gambar 5 : Pembukaan Tahap 2

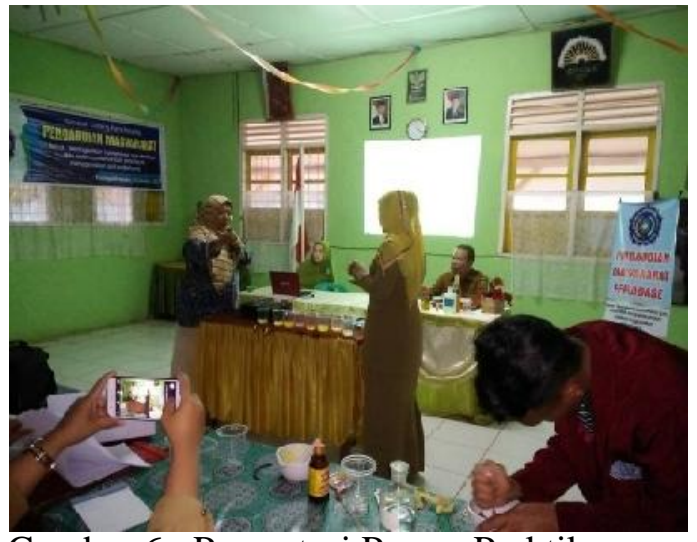

Gambar 6 : Presentasi Proses Praktikum

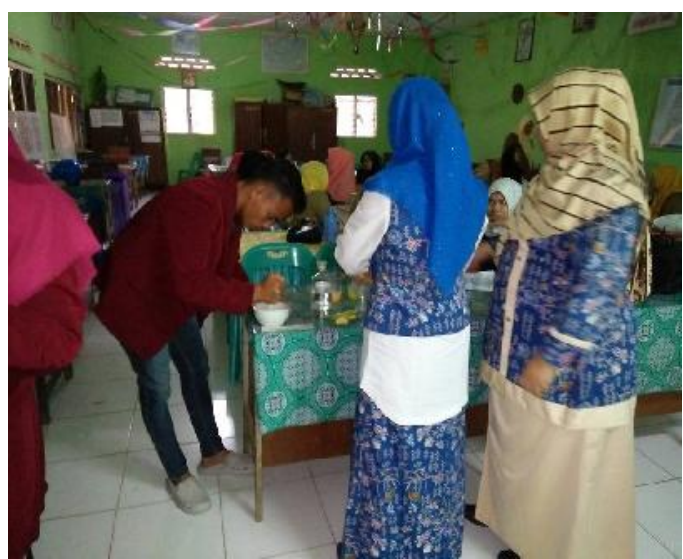

Gambar 7 : Pelaksanaan Praktikum
Kegiatan ini dapat dikatakan berhasil dan terlaksana hal ini juga didasarkan pada antusias para peserta mengikuti kegiatan dan antusias dalam mengajukan pertanyaan. Berikut adalah pertanyaanpertanyaan yang diajukan para peserta workshop:

(1) Bagaimana apabila alat dan bahan praktikum ada yang diganti?

(2) Dalam melaksanakan praktikum model pembelajaran apa yang tepat?

(3) Kenapa reaksi dari praktikum berbeda -beda?

(4) Seperti apa tehnik penilaian yang dilaksanakan agar efisien dan mudah dikerjakan oleh guru?

Penggunaan alat dan bahan itu sebaiknya melibatkan lingkungan sekitar ataupun kehidupan sehari-hari para siswa. Jika kita melibatkan lingkungan sekitar siswa bagaimana siswa kita akan mengetahui lingkungan di luar lingkungannya. Apakah ini tidak akan membuat siswa kita tidak mampu bersaing dengan sekolah lainnya?

Berdasarkan pengamatan terhadap pertanyaan-pertanyaan yang diajukan oleh para peserta terlihat bahwa para peserta sudah memiliki gambaran terkait pelaksanaan praktikum menggunakan alat dan bahan sederhana. Peserta workshop juga antusian mengikuti jalannya kegiatan workshop ini dapat dilihat dari banyaknya peserta yang merespon/bertanya terkait materi yang disajikan. Berdasarkan jenis pertanyaan yang diajukan maka dapat disimpulkan bahwa para peserta sudah banyak memiliki informasi/pengetahuan sehingga kegiatan yang dilaksanakan dapat terlaksana sesuai yang diharapkan..

Hasil tahap ke-1 dan tahap ke-2 menunjukkan bahwa kegiatan workshop dapat berjalan sesuai yang direncanakan. Ini didasarkan pada antusias peserta dalam 
mengikuti dan mengajukan pertanyaanpertanyaan terkait materi yang disampaikan. Berdasarkan hal tersebut maka guru-guru MGMP Biologi sePadangsidimpuan sudah banyak memperoleh motivasi, informasi/ pengetahuan terkait praktikum sederhana dan juga diperkirakan kedepannya para guru-guru MGMP khususnya Biologi di tingkat SMA sudah mampu mengembangkan kreativitas dan kompetensi sendiri.

\section{SIMPULAN}

Berdasarkan hasil kegiatan workshop yang sudah dilakukan, maka diperoleh kesimpulan sebagai berikut: (1) Diperoleh feedback yang positif dari pihak sekolah, guru-guru MGMP Biologi SMA se-Padangsidimpuan selama mengikuti kegiatan workshop. (2) Bertambahnya informasi, pengetahuan, dan pemahaman guru-guru MGMP Biologi sePadangsidimpuan terkait dalam pengembangan alat dan bahan praktikum sederhana. (3) Guru-guru MGMP Biologi se-Padangsidimpuan sudah mampu merancang dan membuat alat praktikum sederhana. (4) Tingginya motivasi yang dimiliki oleh guru-guru MGMP Biologi se -Padangsidimpuan dalam melaksanakan kegiatan workshop

\section{UCAPAN TERIMA KASIH}

Penulis ucapkan terimakasih kepada Universitas Muhammadiyah Tapanuli Selatan yang telah membiayai pengabdian ini, Lembaga Penelitian dan Pengabdian Masyarakat UMTS yang telah memfasilitasi pelaksanaan Pengabdian, MGMP Biologi SMA Se-Kota Padangsidimpuan, Semua yang memfasilitasi pelaksanaan Pengabdian di SMA Negeri 5 Padangsidimpuan dan semua pihak yang tidak bisa penulis sebutkan dalam naskah ini.

\section{DAFTAR PUSTAKA}

Anwar Edi Daenuri. 2014. Pelatihan

Pembuatan Alat-Alat Praktikum

IPA - Fisika bagi Guru IPA

SMP/MTs Swasta Sekecamatan

Winong Kab Pati. Dimas Vol.14

No.1

Yuliati, dkk. 2008. Pelatihan Implementasi "Life Skill" Pada Pembelajaran IPA-Biologi Melalui Kegiatan Pembuatan LKS Model Empirik Bagi Guru SMP. Bantul DIY 